\title{
Classification of Interactive System Components Enables Planning Heuristic Evaluation Easier
}

\author{
Llúcia Masip, Marta Oliva, and Toni Granollers \\ Department of computer science and industrial engineering \\ University of Lleida, Spain \\ \{lluciamaar, oliva, tonig\}@diei.udl.cat
}

\begin{abstract}
Nowadays, new technology continually is turning up and it has incorporated different interactive systems. In a parallel way, people use these technologies and they have to use IS to resolve their tasks without taking into account technology complexities. We consider that the user experience includes a lot of different paradigm that are able to provide users with a positive experience. In this context, our work is focused on enhancing one of the most used usability evaluation techniques. It is an inspection technique that allows carrying out usability reviews without the need of end users. It is called heuristic evaluation. The most difficult task in the heuristic evaluation method is choosing the most suitable set of heuristics for specific interfaces because usability experts have to consider all heuristics and they have to choose the best heuristics for a specific interface. So, the expert evaluator has to know all heuristic and all parts of interactive systems perfectly to find a closed set of heuristics. To make this step easier, we consider that if we have an interactive system component classification, we will be able to detect what components have our interactive system and, to choose the best usability heuristic for each interactive system component. Therefore, we present IS categorization that we will use to decide what heuristics are the best for specific IS according to the main aims of heuristic evaluation.
\end{abstract}

Keywords: interactive system components, heuristic evaluation, usability, classification, user experience.

\section{Introduction}

Nowadays, new technology continually is turning up and it has incorporated different interactive systems (IS). In a parallel way, people use these technologies and they have to use IS to resolve their tasks without taking into account technology complexities. So, IS should be easy to use and IS should create positive feelings and comments to achieve a high satisfaction. Therefore, when users use an interactive system, they should feel a positive user experience.

We consider that the user experience includes many different facets that are able to provide users with a positive experience. Nowadays, different facets have appeared to consider user experience in interactive system design like emotions [1], communicability [2], playability [3], cross-cultural [4] among others. But the oldest and most 
used facet that user experience experts consider when they have to design an interactive system is usability like effectiveness, efficiency and satisfaction that a specific user achieves when he or she uses a specific interactive system in a concrete context of use [4].

Then, usability is an IS feature related to the easiness or difficulty when people use an interactive interface. And, the Human-Computer Interaction discipline provides, among others, a complete set of techniques to evaluate the usability of IS. These techniques are classified in inspection, inquiry and testing techniques [5] [6].

We carried out an exhaustive search for finding user experience evaluation, but we could not find methods including more than one user experience facet. So, we based it on one of the most used methods to assess the oldest user experience facets. It is called heuristic evaluation. It is an inspection technique that allows carrying out usability reviews without the need of end users [5].

Although we based it on the heuristic evaluation method, we wanted to go a step further. If we want to evaluate user experience in an interactive system, we obviously should include end users in the evaluation process. Additionally, we do not want to forget the first use of heuristics. The first heuristics that appeared were advice, or guidelines, to be followed when designing a specific interactive interface. Thus, only with these two premises we detected three different user profiles where each user profile needs to use heuristics in a different way. These profiles are designers, end user evaluators and expert evaluators.

Thus, we based it on the heuristic evaluation process to assess user experience but including different user profiles that will be able to score the heuristics for a specific interactive system.

In this context, our work is focused on enhancing the first step of one of the most used usability evaluation techniques.

To perform an HE it is necessary to complete three steps: planning the evaluation, scoring the heuristics and extracting results. Even knowing that our main and global objective is semi-automation of the HE process, in this paper we have concentrated on the first step: planning the evaluation.

Planning an evaluation implies (i) choosing evaluators, (ii) fixing the most suitable set of rules for the specific interface and, (iii) determining the severity factors to decide on heuristics marks. The most difficult task in this first step is choosing the most suitable set of heuristic for a specific interface. It is the most difficult task because usability experts have to consider all heuristics and they have to choose the best heuristics for a specific interface. So, expert evaluators have to know all heuristics and all parts of an interactive system perfectly, because they have to be able to find a closed set of heuristics that cover each usability feature of each interactive system part.

To make this step easier, we consider that if we have a classification of interactive system components, we will be able to detect what components have our interactive system and, we will be able to choose the best usability heuristic for each interactive system component.

Therefore, we present IS categorization that we will use to decide what heuristics are the best for specific IS according to the main aims of HE. In section 2, we present two real experiences that justify the need of improving heuristic choices. Then, we show related classifications of interactive system components presented by other researchers and next, we explain our classification of hardware and software 
components. And in addition we detail a discussion about it. Finally, conclusions and future works in this research area are presented.

\section{Real Experiences}

In this section we show two real usability evaluations in very different interactive systems that reveal difficulties that we had when we chose the best heuristics for each interactive system.

A year ago, the Lleida City Council wanted to evaluate the usability of two new public interfaces that offered services to their citizens. In this section, we want to present both experiences that we were involved in and, then, our motivation for carrying out this work.

The first experience concerns the usability analysis of a virtual website assistant. Second is about the usability and accessibility analysis of interactive physical devices called PIC (Citizens Information Point). The following sub-sections delve into the details of both evaluations.

\subsection{Virtual Assistant}

Berta is a new virtual assistant provided by the Lleida City Council in its website (http://www.paeria.es). Its main function is to help users to find information about different online procedures that citizens can do in Lleida using its website.

The Computer Department of the Lleida City Council hired us because they were worried about the usability level of their virtual assistant. After starting, those responsible warned us that they can change assistant faces and dialogs used but they cannot modify the interface codification, because it is an external application.

So, they were not interested in usability problems concerning the interface design. Their main interest was about facial expression problems and dialog problems. Taking into account that facial expressions are connected with the dialog used and all this depends on the vocabulary used for end users.

With this information, we studied their pre-requirement and we were aware that we could not use the same heuristic that we used in a common website. We had a different interactive system with different features and our usability goal was completely different from previous experiences that were a good challenge for us.

Finally, we decided to perform a heuristic evaluation ruling out common heuristics. We did not consider it because it did not cover the main objectives of usability evaluation and we considered that the most popular heuristics were not suitable for corporal expressions, dialog and vocabulary used.

So, we reviewed literature to collect heuristics for this type of interactive system and we did not find a concrete set of heuristics which covers the usability features commented above. However, we found four sources that we could mix up to achieve a complete set of usability heuristics for covering all features for virtual assistants. These works are about question-answer systems [7], dialog management in virtual assistants [8], best practices for speaking avatar design [9] and emotional heuristics [10]. Although these works do not present heuristics themselves, we could extract information to consider it for creating heuristics for our concrete features in the virtual assistant. 


\subsection{Public Kiosks}

The second real experience was the usability and accessibility evaluation of interactive public kiosks called PIC (Citizen Information Point) [11]. PIC is a physical device located in public buildings spread throughout the city.

Every PIC allows achieving a large set of public procedures such as obtaining certificates or reviewing personal and local information. PICs are also provided with a printer, keyboard, mouse, screen and digital signature reader through cryptographic card, electronic identity card or USB flash drive. It is like a cash machine, but with computer capability and redesigned elements for those specific locations and situations.

In this case, the main goal was not interfaces that we could see on screen. The main aim was to evaluate usability and accessibility according to their specific localization and their particular physical features.

Thus, we saw that we could not use the most used heuristics (like Nielsen's) because these heuristics, in the same way like experience above, did not cover our evaluation goals and all the features of PICs.

In this case, we used many works to collect a complete set of usability and accessibility heuristics for covering all features of this kind of interactive system. We considered literature about design and evaluation in public kiosks [12] [13] [14] [15] and design and evaluation in general [16] [17]. We also considered notable information extracted from some Internet blogs with confirmed references such as [18] [19]. Apart from these references, we mainly used guidelines of current regulation about digital accessibility such as UNE139801: 2003 and UNE139802: 2003 [20] [21].

With all these articles we could collect a large set of heuristics to evaluate the usability and accessibility of our public kiosk.

\subsection{Real Experiences Discussion}

As we have seen, every IS has its own features and usability goals widely differ between common websites and virtual assistant interfaces or physical devices. The first aspect we noticed was that we could not use the most used heuristics (like Nielsen's) in both experiences because these heuristics did not cover our evaluations aims and all features of Berta and PICs. Furthermore, the bibliography studied did not provide us specific rules to guide our studies, and then our first difficulty was how awkward it was to choose the most suitable heuristics for those cases. There is no formal and specific definition about usability heuristics for "any kind of IS", and that was our first goal to achieve.

We started searching as much as possible the usability heuristic definitions existing up to now. It is obvious that a lot of researchers have worked to define and modify heuristics concepts. We reviewed all general usability heuristics defined since 1986 and we detected 16 repeated categories. In addition, we concluded in this previous work that 16 categories are applicable in simple websites or desktop applications. To sum up, we consider that 16 categories have to adapt to cover all possible usability aspects that we can find in each interactive interface [22].

Once we have the usability categories, we need to adapt all of them to every kind of IS. Additionally, HE sometimes has specific goals like purchasing, localization or hardware devices, among others. Therefore, it is clear that usability experts have to 
begin the choice of heuristics determining what parts of IS they want to consider in HE. Even so, if usability experts detect what parts they want to evaluate, the way to choose the best heuristic will become easier, and we justify this in next section.

\section{Interactive Systems Classification}

What was the way we followed to choose the best heuristics for virtual assistants and public kiosks? We had a large set of heuristics cited in [22] and we reviewed all of them to decide if we could use them to assess some part of our new interactive system. Apart from this review, one of the times we wasted the most was when deciding what parts or components should be chosen for a usability evaluation of those systems. So, we spent time to make some efforts to detect public kiosk and virtual assistant components. And, obviously, we considered common websites in the components search. We achieved a classification of interactive systems components that permitted us to know what parts of the interactive system should be assessed and chose the best heuristics for each part. To sum up, this classification makes planning heuristic evaluation easier.

As a result, we proposes a classification of IS components. We divided IS into two big groups: software IS and hardware IS. We use this classification because we consider that software and hardware systems have different features or components that involve different types of specific heuristics. So, we presented a classification for software and hardware interactive interfaces. Then, some categories (but not all of them) are divided in more components to allow a complete classification of IS components in order to facilitate their evaluation. In the following sections, we detail more about interactive system classification. It is based on website and avatar parts to detect software classification and public kiosk components to show hardware classification.

\subsection{Related Classifications of Interactive Systems Components}

We did an exhaustive search in literature to find any classification of interactive system components but, unfortunately, we did not find many works about it.

We have highlighted elements detected by Jakob Nielsen and Kara Pernice in their new book "Eyetracking web usability" [23]. The book presents fundamental website design elements in chapter 5. Their list of elements permits designers to consider all the parts in a website design but they do not specify enough to consider all of the elements in our classification. We consider that some of elements presented in the book can be used in a further step for including these elements in our classification of interactive system components. For example, in the book, the shopping cart is considered fundamental in a website design. So, as a future work, we will consider shopping cart implies forms, numerical values, nomenclature, icons and information validation, among others as components in our classification.

Another work related to the classification of interactive system components is [24]. In this work we found a classification of parts of videogames. The way that the author developed his idea is very interesting for achieving a conceptual model of the parts detected in this type of interactive system. But this model only includes specific interactive systems and we wanted to cover a larger set of them. 
So, we did not find a classification that includes specific parts of the most used interactive system such as common websites, virtual assistants or public kiosks. In the next section we present a classification of interactive system components including all parts of these interfaces.

\subsection{Software Interactive Systems}

We consider that software interactive systems are the systems that include some type of software such as websites, desktop applications, video recorders, and mobile phone interfaces. But in addition, we should consider all hardware systems that also include software parts (although this software part will be a little part of a big hardware system). For instance, public kiosk or some electrical appliance, among others, have important hardware components but they also provide us with a little software interface that we cannot forget when we want to carry out a complete user experience evaluation.

According to our past evaluations of common websites, virtual assistants and desktop applications, we can detect some components that are susceptible to a user experience evaluation. So, our classification of software interactive system components shows a complete set of software components that we can detect in many types of interactive systems. To sum up, we present in the next table a classification of software interactive system components that we can use to detect each part of most software interactive systems.

Table 1. Classification of software interactive system components

\begin{tabular}{ll}
\hline General group & Specific feature \\
\hline Type of content & Forms, tables, lists, dates, times, numerical values, money signs \\
Information & $\begin{array}{l}\text { Pictures, news, graphics, format, text, URL, abbreviations, audio, } \\
\text { nomenclature, colours, icons }\end{array}$ \\
Data management & $\begin{array}{l}\text { Information transmission, sign in form, log in form, updating } \\
\text { information, information validation, information recovery }\end{array}$ \\
Search & Search form, results of search \\
$\begin{array}{l}\text { Navigation area } \\
\text { Emergency exits }\end{array}$ & Pages, titles, cursor, shortcuts \\
\hline
\end{tabular}

\subsection{Hardware Interactive Systems}

We know hardware interfaces as some physical devices that you can interact with it. Some examples are elevator panels, public kiosks, video recorders, ovens...

As above, we were faced with the challenge to choose which "hard" components of the public kiosk should be analysed. We highlight that a public kiosk, as a physical system, is a complete interactive system with a large set of components and a software part. 
So, hardware interfaces are classified into operative systems, navigator, in/out devices, assistive aids, audio, indicators and help and documentation. Then, every category is divided in more components to allow a complete hardware IS classification in order to facilitate its evaluation.

The hardware interactive system categorization is:

Table 2. Classification of hardware interactive system components

\begin{tabular}{ll}
\hline General group & Specific feature \\
\hline $\begin{array}{l}\text { Operating system } \\
\text { Navigator }\end{array}$ & \\
In/out devices & $\begin{array}{l}\text { Printer, digital certificate, electronic card, mouse, } \\
\text { screen, keyboard }\end{array}$ \\
Assistive aids & Icons, assistive hardware \\
Audio & Volume \\
Indicators & \\
Help and documentation & \\
\hline
\end{tabular}

\subsection{Interactive System Components Discussion}

Note that in hardware classification we include software components such as operating systems or navigators. It is because hardware systems might provide us with software applications and we consider that the same type of hardware interactive system should include the same version of operating system or navigator to avoid confusion for users when they use these systems.

In addition, we should consider that sometimes, IS includes software components. Therefore, this classification is not a mutually exclusive classification but it is a complementary classification because the hardware and software components of systems might be found in a concrete interactive system such as public kiosks.

It is also obvious that sometimes some heuristics can take part in more than one part of an interactive system. For example, there are some heuristics like "the same things have to be aesthetically equals", so it is applicable in indicators, keys, icons, among others. So, some heuristics are the best for more than one of the interactive system components. But we consider that if we know perfectly which components of our interactive system we want to evaluate or which components should be considered, we will be able to choose the best heuristic for each component more easily.

\section{Conclusions}

In conclusion, we want to concentrate all importance in IS when we want to do an HE. We have an interface and it is the centre of our minds. Then, we can decide what type of goals we want to consider in evaluation: usability features or components of 
IS. And we should be able to choose the best heuristics with both types of evaluation aims.

In this work we presented a classification of interactive system components because our main problem when we carry out a user experience evaluation through a heuristic evaluation in a new interactive system is detecting all interactive system components of our system for choosing the best heuristics for each component. Thus, we consider that if we have a classification and this classification is linked to specific heuristics (this is part of our future work), we will obtain the best heuristics for an interactive system more easily and in a more comfortable way than if we have to review each interactive system, detect all parts, look for the best heuristics and so on.

Finally, we know that this classification is not a closed group. It is the first step in achieving a large and complete classification of all interactive systems.

As a future work, we want to achieve a general and complete classification of interactive system components because we want to be able to detect interactive system components with a general goal of interface. For instance, if we have a website, we will detect that the website includes a main part of privacy and forms because this website is an online shop. So, we think it will be possible if we consider interaction patterns in our project.

Acknowledgments. The work described in this paper has been partially supported by Spanish Ministry of Science and Innovation through the Open Platform for Multichannel Content Distribution Management (OMediaDis) research project (TIN200806228) and it has been partially supported by Universitat de Lleida for pre-doctoral fellowship to Llúcia Masip. An acknowledge to Development of Adaptive and Collaborative Systems (DESACO) research project (TIN2008-06596-C02-01/TIN) also must be done.

\section{References}

1. Leitner, G., Hitz, M., Melcher, R.: The Role of Usability in the Design and Evaluation of Dynamic Traffic Displays. In: Holzinger, A. (ed.) USAB 2008. LNCS, vol. 5298, pp. 205220. Springer, Heidelberg (2008), doi:10.1007/978-3-540-89350-9_15

2. Prates, R., de Souza, C., Barbosa, S.: Methods and tools: a method for evaluating the communicability of user interfaces. Interactions 7(1), 31-38 (2000),

http: / / doi.acm.org/10.1145/328595.328608

3. González, J.L., Padilla, N., Gutiérrez, F.: From Usability to Playability: Introduction to Player-Centred Video Game Development Process. In: Kurosu, M. (ed.) HCD 2009. LNCS, vol. 5619, pp. 65-74. Springer, Heidelberg (2009)

4. Jiang, O., De Bruijn, O., De, A.: The Perception of Cultural Differences. In Online Selfpresentation. In: Gross, T., Gulliksen, J., Kotzé, P., Oestreicher, L., Palanque, P., Prates, R.O., Winckler, M. (eds.) INTERACT 2009. LNCS, vol. 5726, pp. 672-685. Springer, Heidelberg (2009)

5. ISO. International Standard ISO/IEC 9126. Information technology - Software product evaluation - Quality characteristics and guidelines for their use, International Organization for Standardization, International Electrotechnical Commission, Geneva (1991)

6. Nielsen, J., Mack, R.L.: Usability Inspection Methods. John Wiley \& Sons, New York (1994) ISBN: 0-471-01877-5 
7. Dix, A., et al.: Human-Computer Interaction. Prentice-Hall, Madrid (2009)

8. Martínez, P., Vicedo, J. L., Saquete, E., Tomás, D.: Sistemas de pregunta-respuesta Universidad de Alicante. Departamento de Lenguajes y Sistemas Informáticos (2007) http://rua.ua.es/dspace/handle/10045/2525

9. Rodrigo, L., García, A., Martínez, P.: Planeamiento semántico y pragmático para gestión de diálogos en asistentes virtuales. Procesamiento del Lenguaje Natural, Revista, num. 28 (2002)

10. Sitepal. Speaking avatar best practices guide (2003), allowed in http://www.sitepal.com/pdf/bestpractice_2008.pdf

11. Lera, E., Garreta, M.: Diez heurísticos emocionales. Revista Faz. num 2, pp. 68-71. Revista de Diseño de Interacción. Barcelona, España (2008)

12. Oliva, M., Masip, L., Granollers, T.: Evaluación de usabilidad y accesibilidad de un conjunto de dispositivos interactivos denominados Puntos de Información Ciudadana. Scire: representación y organización del conocimiento 16, 35-46 (2010)

13. Maguire, M.C.: A Review of User-Interface Design Guidelines for Public Information Kiosk Systems. In: Stephanidis, C., Carbonell, N. (eds.) Electronic Proceedings of the 3rd ERCIM Workshop on User Interfaces for All (1997), http: / /ui4all.ics.forth.gr/UI4ALL-97/maguire.pdf (15/09/2008)

14. Nieto, M.: La usabilidad de los terminales táctiles. Evolucy (2002), http: / / www.evolucy.com/esp/columns / 20020515 _usabilidad_tactil . html (15-7-2009)

15. Gutiérrez, M.: ¡Larga vida de los cajerosi, Revista Faz. November 2007 número 1, http: / /www.revistafaz.org/numero1/cajeros.pdf (19/09/2008)

16. Evolucy. Evaluación heurística de un quiosco de autoservicio de fotografía digital: caso práctico (2004), http://www.evolucy.com/esp/projects/evaluacion_ heuristica_kiosk.html (8-7-2009)

17. Granollers, T., Lorés, J., Cañas, J.J.: Diseño de sistemas interactivos centrados en el usuario. Editorial UOC, Barcelona (2005) ISBN: 84-9788-320-9

18. Sidar, F.: Principios del Diseño Universal o Diseño para Todos (19/09/2008), http: / / www. sidar.org/recur/desdi/usable/dudt.php

19. Usable y Accesible (19/09/2008), http: / / olgacarreras.blogspot.com/

20. facilusar.com. (19/09/2008), http: / / facilusar.blogspot.com/

21. UNE139801. Aplicaciones informáticas para personas con discapacidad. Requisitos de accesibilidad al ordenador. Hardware. AENOR. Depósito legal: M 42219:2003 (2003)

22. UNE139802. Aplicaciones informáticas para personas con discapacidad. Requisitos de accesibilidad al ordenador. Software. AENOR. Depósito legal: M 42220:2003 (2003)

23. Masip, L., Oliva, M., Granollers, T.: Hacia la semiautomatización de la evaluación heurística: Primer paso, categorización de heurísticas, Interacción 2010, Grupo Editorial Garceta, Valencia, September 7-10, pp. 359-368 (2010)

24. Nielsen, J., Pernice, K.: Eyetracking web usability. New Riders, Berkeley (2010) ISBN 9780321498366 (pbk.) 0321498364 (pbk.)

25. González, J.L.: Jugabilidad: caracterización de la experiencia del jugador en videojuegos. Doctoral Thesis. Universidad de Granada (2010) 